\title{
Ionic conduction in poly(ethylene carbonate)-based rubbery electrolytes including lithium salts
}

\author{
Polymer Journal (2012) 44, 1155-1158; doi:10.1038/pj.2012.97; published online 20 June 2012
}

\section{INTRODUCTION}

Ion-conductive polymers are recently developed electrolyte materials that are suitable for electrochemical applications, such as Li-ion secondary batteries, ${ }^{1,2}$ because they are safe (not flammable, no leakage), lightweight, easily processed and flexible. Ionic conduction in poly(ethylene oxide) (PEO)metal salt complexes was reported in $1973,{ }^{3}$ and there have since been many studies of the macromolecular design of PEO-based polymers as electrolyte materials that addressed reducing degrees of crystallinity as well as the exhibition of good conductivity and superior salt solubility. ${ }^{4-6}$ However, these electrolytes suffer from low conductivity in the solid state relative to liquid or gel electrolytes. The maximum conductivity of amorphous polyether-based electrolytes is $\sim 8 \times 10^{-5} \mathrm{~S} \cdot \mathrm{cm}^{-1}$ at $25^{\circ} \mathrm{C}$, and it is difficult to exceed values on the order of $10^{-5}$ at room temperature. The migration of ions in PEO arises from the local motion of oxyethylene chains in the amorphous region. The local structure that is crucial to the migration is believed to participate in cation-dipole interactions. ${ }^{4}$ In fact, the interaction sometimes inhibits the fast migration of ions (esp. cations), because the oxyethylene chains coordinate cations with the dipoles and form complex structures, which increases the glass transition temperature, $T_{\mathrm{g}}$. Novel polymer candidates without oxyethylene units are needed to overcome these problems.

We shall consider polycarbonates that can be obtained by the alternating copolymerization of carbon dioxide with epoxides and comprise novel polymer candidates for electrolytes. Following the first report of the $\mathrm{CO}_{2}$ /epoxide copolymer by the Tsuruta group, ${ }^{8,9}$ there has been considerable development of highly active catalysts for effective polymerization. ${ }^{10}$ This copolymer is a remarkable macromolecule, because it utilizes $\mathrm{CO}_{2}$ as a raw material and has excellent properties; it is biodegradable, easily processed and colored, and has high transparency and low oxygen permeability. We have focused on the chemical structure of the copolymer, which has one alternating carbonate group $(-\mathrm{O}-(\mathrm{C}=\mathrm{O})-\mathrm{O}-)$ in each repeating unit of the main chain. The carbonate group has a large dipole moment, and it can dissolve many types of salts. Carbonatebased organic solvents, such as dimethyl carbonate, are used as the electrolyte solution in Li-ion batteries because of their high dielectric constant. Therefore, the carbonate group provides a suitable structure for the polymer framework. Polycarbonate-based electrolyte systems, such as poly(vinylene carbonate ${ }^{11}$ and poly(trimethylene carbonate), ${ }^{12}$ have previously been reported. We recently synthesized glycidyl ether-based polycarbonates and have measured the ionic conductivities of these electrolytes. ${ }^{13,14}$ In our previous studies, it was impossible to determine the ion-conductive properties of these polycarbonates because of poor yields. In the present paper, we used a commercial, readily available polycarbonate, poly(ethylene carbonate) (PEC) for a polymer matrix, and we prepared five types of $\mathrm{Li}$ electrolytes with salt concentration varying from 16 to $80 \mathrm{wt} \%$.

\section{EXPERIMENTAL PROCEDURE}

PEC was donated by Sumitomo Seika Co. (Osaka, Japan). The as-received chloroform solution of PEC was added into excess methanol, and the precipitated PEC was then dried in a vacuum oven at $60^{\circ} \mathrm{C}$ for $24 \mathrm{~h}$. The ${ }^{1} \mathrm{H}$ and ${ }^{13} \mathrm{C}$ NMR spectra of the purified PEC $\left(M_{n}=3.7 \times 10^{4}, \quad M_{w} / M_{n}=5.9\right)$ were measured using a JEOL EX-400. The ratio of the carbonate units to all units (carbonate and ethylene oxide units) in the main chain was determined to be $95.2 \%$ from the
${ }^{1} \mathrm{H}$ NMR measurement (see Supplementary Figure S1 of Supplementary Information). Poly[ethylene oxide-co-2-(2-methoxyethoxy)ethyl glycidyl ether], $\mathrm{P}(\mathrm{EO} / \mathrm{EM} 2)$, was donated by the Daiso Co. (Osaka, Japan) The $m / n$ ratio was determined to be $83 / 17$ from the ${ }^{1} \mathrm{H}$ NMR measurement. Figure 1 shows the chemical structures of these polymers. To prepare the electrolyte samples, PEC or $\mathrm{P}(\mathrm{EO} / \mathrm{EM} 2)$ was dissolved in acetonitrile with lithium salts, $\mathrm{LiX}$ (anion $\mathrm{X}=$ $\mathrm{N}\left(\mathrm{SO}_{2} \mathrm{CF}_{3}\right)_{2}$ (TFSI), $\mathrm{N}\left(\mathrm{SO}_{2} \mathrm{C}_{2} \mathrm{~F}_{5}\right)_{2}$ (BETI), $\mathrm{BF}_{4}, \mathrm{ClO}_{4}$ and $\mathrm{CF}_{3} \mathrm{SO}_{3}$ ), and the solution was cast onto the plastic dish. The solution was held for several hours in a dry $\mathrm{N}_{2}$-filled circulation chamber and then dried under vacuum at $60^{\circ} \mathrm{C}$ for $24 \mathrm{~h}$. Differential scanning calorimetry (DSC) measurements of all samples were performed using a DSC120 (Seiko Inst., Chiba, Japan) in the temperature range $-100{ }^{\circ} \mathrm{C}$ to $250^{\circ} \mathrm{C}$ at a heating rate of $10^{\circ} \mathrm{C} \cdot \min ^{-1}$ under dry $\mathrm{N}_{2}$ gas. The ionic conductivities of all electrolytes were measured using the complex impedance method with a potentiostat/galvanostat SP-150 (BioLogic, Claix, France) in the frequency range of $100 \mathrm{~Hz}$ to $1 \mathrm{MHz}$ in a glove box filled with dry Ar gas.

\section{RESULTS AND DISCUSSION}

The PEC electrolytes obtained using Li salt concentrations varying from 16 to $60 \mathrm{wt} \%$ were all self-standing films, and those prepared with a Li salt concentration of $80 \mathrm{wt} \%$ were rubbery solids. The electrolytes including LiTFSI, LiBETI and $\mathrm{LiBF}_{4}$ were transparent, but the electrolytes including $\mathrm{LiClO}_{4}$ (except for the 20 and $40 \mathrm{wt} \%$ samples) and $\mathrm{LiCF}_{3} \mathrm{SO}_{3}$ became opaque films. Figure 2 shows the DSC traces of the neat PEC and the PEC-LiTFSI electrolytes. The neat PEC had an obvious glass transition at $9^{\circ} \mathrm{C}$ and was an amorphous polymer, because there were no remarkable transitions between 
$T_{\mathrm{g}}$ and the degradation temperature at $\sim 220^{\circ} \mathrm{C}$. The neat LiTFSI underwent a solid-solid transition at $163^{\circ} \mathrm{C}$ and melted at $235^{\circ} \mathrm{C}$ (see Supplementary Figure S2 of Supplementary Information). However, the $T_{\mathrm{g}}$ value of the PEC-LiTFSI electrolytes gradually decreased with increasing salt concentration. The $T_{\mathrm{g}}$ value of the PEC electrolyte with an $80 \mathrm{wt} \%$ salt concentration was the lowest, at $-62{ }^{\circ} \mathrm{C}$, and the difference between the $T_{\mathrm{g}}$ values for the $80 \mathrm{wt} \%$ electrolyte and the neat PEC was more than $70{ }^{\circ} \mathrm{C}$. It is well known that the $T_{\mathrm{g}}$ for polyether-based electrolytes usually increases with the concentration of salt added. ${ }^{4-7}$ The decrease in the $T_{\mathrm{g}}$ of PEC was considered to be due to the plasticizing effect of the dissociated TFSI anions, ${ }^{15}$ but these decreases cannot be explained by the anionic effect alone. In addition, a small transition was observed at $\sim-15^{\circ} \mathrm{C}$ in the $80 \mathrm{wt} \%$ electrolyte and may be because of the $T_{\mathrm{g}}$ value of LiTFSI. This small transition means that a small amount of LiTFSI aggregates are partially separated from the PEC electrolyte.

The temperature dependence of the ionic conductivity for the PEC-LiTFSI electrolytes is shown in Figure 3. The conductivity increases with increasing LiTFSI concentration, and the $80 \mathrm{wt} \%$ electrolyte has the greatest conductivity. The value of the ionic conductivity for the $80 \mathrm{wt} \%$ electrolyte at $30^{\circ} \mathrm{C}$ was $\sim 0.5 \times 10^{-5} \mathrm{~S} \mathrm{~cm}^{-1}$, which is more than 120 times greater than that of the $20 \mathrm{wt} \%$ electrolyte. The plot for the $20 \mathrm{wt} \%$ electrolyte reveals the highest gradient, and the gradient decreases slightly with increasing salt concentration. All plots exhibited the typical Arrhenius behavior, which is similar to the polyether-based amorphous electrolytes, and are convex throughout the entire range of measurement temperature. The temperature dependence of the amorphous polymer electrolytes follows the modified VTF equation ${ }^{5}$

$$
\begin{aligned}
\ln \left(\sigma \cdot T^{1 / 2}\right)= & -E_{\mathrm{a}} / R\left(T-T_{0}\right) \\
& +\ln A
\end{aligned}
$$

where $A\left(\mathrm{~K}^{1 / 2} \cdot \mathrm{S} \cdot \mathrm{cm}^{-1}\right)$ is a constant that is proportional to the number of carrier ions, $T_{0}$ is the ideal $T_{\mathrm{g}}$ value $\left(T_{0}=T_{\mathrm{g}}-50 \mathrm{~K}\right), R$ is the fundamental gas constant and $E_{\mathrm{a}}$ $\left(\mathrm{kJ} \cdot \mathrm{mol}^{-1}\right)$ is the activation energy for ionic transport via segmental motion. ${ }^{5}$ The parameters $A$ and $E_{\mathrm{a}}$ can be estimated from the intercept and the gradient of each linear plot based on the VTF equation. From the VTF fitting in Figure 3, it can be observed that the PEC-LiTFSI electrolytes clearly follow this equation; therefore, the ionic

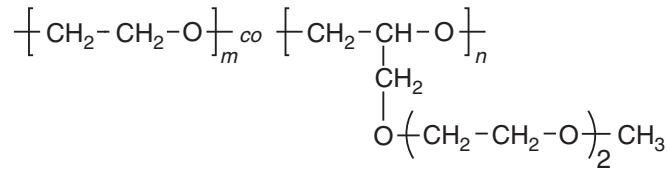

$\mathrm{P}(\mathrm{EO} / \mathrm{EM} 2)$

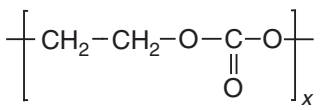

$\underline{\text { PEC }}$

Figure 1 Chemical structures of $\mathrm{P}(\mathrm{EO} / \mathrm{EM} 2)$ and PEC.

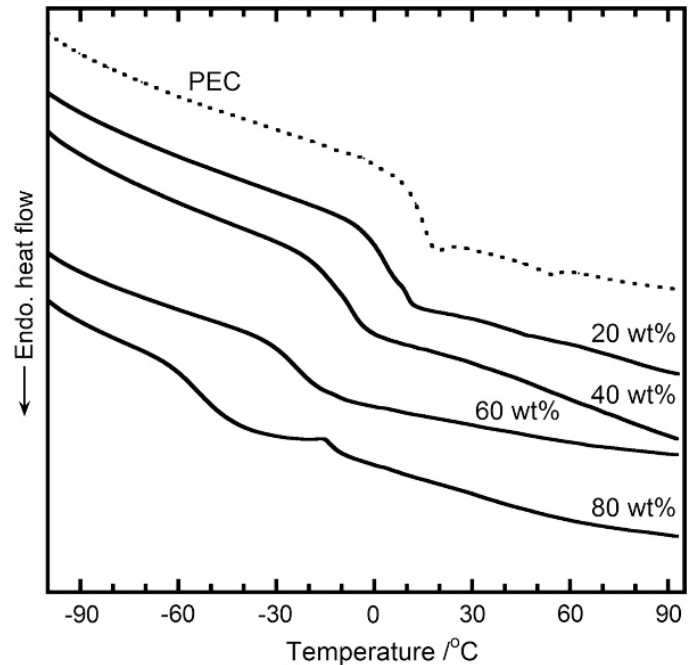

Figure 2 DSC traces of PEC, LiTFSI and PEC-LiTFSI electrolytes with various salt concentrations (20-80 wt\%).

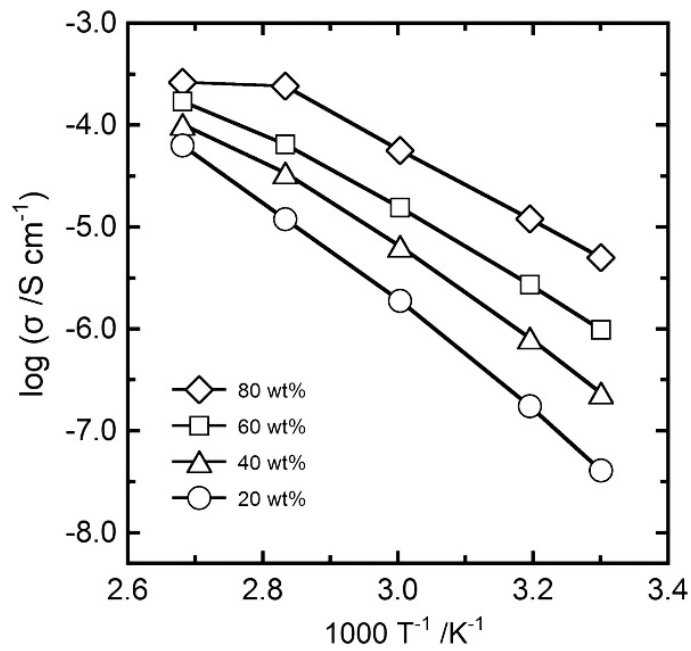

Figure 3 Temperature dependence of the ionic conductivity for the PEC-LiTFSI electrolytes with various salt concentrations (20-80 wt\%). 

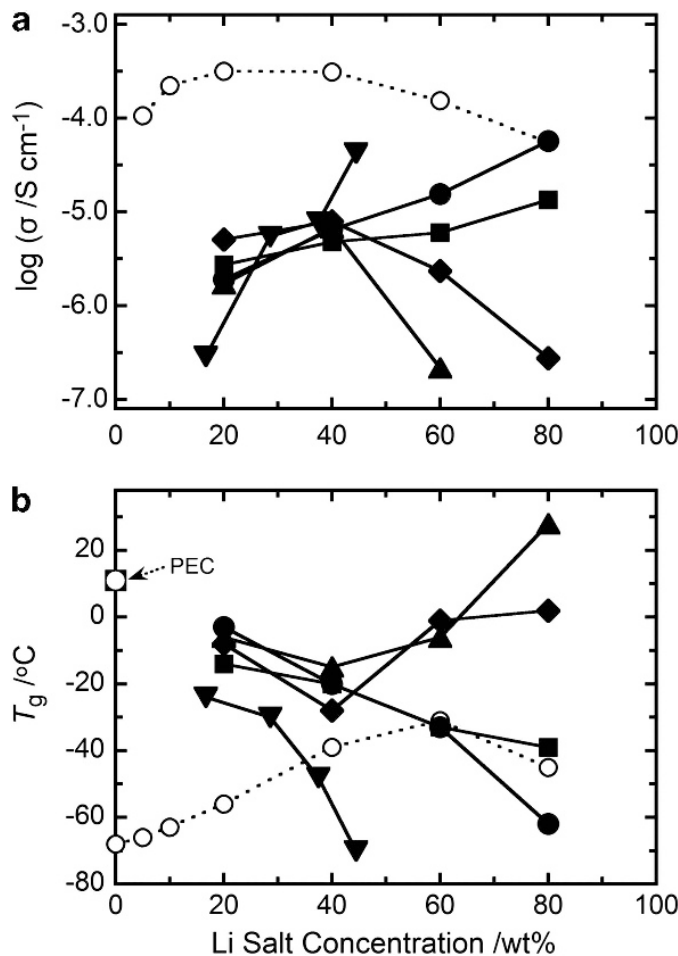

Figure 4 Variation with $\mathrm{Li}$ salt concentration of (a) ionic conductivity at $60^{\circ} \mathrm{C}$ and (b) $\mathrm{T}_{\mathrm{g}}$ of PEC-LiX (anion X $=$ TFSI: $, \mathrm{BETI}: \mathbf{\square}, \mathrm{BF}_{4}: \mathbf{\nabla}, \mathrm{ClO}_{4}: \diamond, \mathrm{CF}_{3} \mathrm{SO}_{3}: \mathbf{\Delta}$ ) and P(EO/EM2)-LiTFSI (O) electrolytes.

conduction in PEC also depends on the segmental motion of the polymer chains. The $A$ and $E_{\mathrm{a}}$ parameters of the PEC electrolytes $(20-80 \mathrm{wt} \%)$ were estimated to be $6-51 \mathrm{~K}^{1 / 2} \cdot \mathrm{S} \cdot \mathrm{cm}^{-1}$ and $11-16 \mathrm{~kJ} \cdot \mathrm{mol}^{-1}$, respectively. The values of $A$ for the PEC electrolytes were slightly higher than for the amorphous $\mathrm{P}(\mathrm{EO} / \mathrm{EM} 2)-\mathrm{LiTFSI}$ electrolytes $\left(5-44 \mathrm{~K}^{1 / 2} \cdot \mathrm{S} \cdot \mathrm{cm}^{-1}\right)$. However, there was no great difference in the $E_{\mathrm{a}}$ values between these electrolyte systems. This behavior has been previously observed in the glycidyl ether-based polycarbonate electrolytes, ${ }^{13}$ indicating that the potential energy for ionic transport in $\mathrm{PEC}$ and $\mathrm{P}(\mathrm{EO} / \mathrm{EM} 2)$ may be almost identical. The carrier ions can migrate, even in the polycarbonate, without ethylene oxide units.

The dependence on salt concentration of the ionic conductivity or $T_{\mathrm{g}}$ for the PEC-LiX and $\mathrm{P}(\mathrm{EO} / \mathrm{EM} 2)$-LiTFSI electrolytes is shown in Figure 4. In Figure 4a, the conductivity of the polyether-based electrolyte was the greatest at a salt concentration of $\sim 20-30 \mathrm{wt} \%(\sim 5$ $\mathrm{mol} \% \mathrm{Li}^{+}$to the oxyethylene units); this behavior of the polyether system is well known. ${ }^{4-7}$ At high salt concentrations, above $40 \mathrm{wt} \%$, the conductivity slowly decreases with increasing concentration. This behavior arises from the increase in crosslinking structures between the cations and the dipoles of the polyether chains. The structure prevents the segmental motion of local chains in the amorphous regions and gives rise to the large increase in $T_{\mathrm{g}}$, as observed in Figure $4 \mathrm{~b}$.

The conduction and glass transition behavior was different for the PEC-based electrolytes. As shown in Figure $4 \mathrm{a}$, the $\mathrm{LiCF}_{3} \mathrm{SO}_{3}$ and $\mathrm{LiClO}_{4}$ electrolytes exhibited the typical polyether-like conduction behavior, but with the maximum values shifted to the higher concentration region, from $20-30$ to $40 \mathrm{wt} \%$. In addition, the conductivities of the LiBETI, $\mathrm{LiBF}_{4}$ and LiTFSI electrolytes increased linearly with increasing concentration, and the electrolyte with $80 \mathrm{wt} \%$ LiTFSI had the highest conductivity of all of the PEC systems. The glass transition behavior of the PEC system is unique. As shown in Figure $4 b$, the $T_{\mathrm{g}}$ value of PEC falls by more than $10^{\circ} \mathrm{C}$ with the addition of salts to at least $16 \mathrm{wt} \%$ of $\mathrm{LiBF}_{4}$, whereas the $T_{\mathrm{g}}$ for $\mathrm{P}(\mathrm{EO} / \mathrm{EM} 2)$ increases with increasing salt concentration. At high salt concentrations (above $40 \mathrm{wt} \%$ ), the $T_{\mathrm{g}}$ for the $\mathrm{LiCF}_{3} \mathrm{SO}_{3}$ and $\mathrm{LiClO}_{4}$ electrolytes increased with increasing concentration. In contrast, for the LiBETI, $\mathrm{LiBF}_{4}$ and LiTFSI electrolytes, the value of $T_{\mathrm{g}}$ decreased with increasing concentration, and the electrolyte with $44.4 \mathrm{wt} \%$ of $\mathrm{LiBF}_{4}$ presented the lowest $T_{\mathrm{g}}$, which was $\sim 80^{\circ} \mathrm{C}$ lower than the $T_{\mathrm{g}}$ of the pure PEC. For salt concentrations from
20 to $80 \mathrm{wt} \%$, the behavior of the PEC-based electrolytes is opposite to that of typical polyether systems. The addition of salts to polyether usually leads to an increase in $T_{\mathrm{g}}$ as a result of the strong interactions of the dissociated $\mathrm{Li}^{+}$with the ether oxygen and coordination with the polymer chains. ${ }^{4}$ For the PEC system, the dipole moment of the carbonate group in the main chain is strong enough to dissociate salts and interact with cations, but tight coordinations or solvations, such as PEO-salt complexes, are negligible. We believe that there are many mobile ions (esp. $\mathrm{Li}^{+}$) in PEC, which can migrate faster than coordinated cations, ion pairs and aggregated ions; the existence of these free ions may be involved in the large decrease in $T_{\mathrm{g}}$. This behavior of the salt-rich PEC electrolytes and the partial P(EO/EM2) electrolytes (more than $60 \mathrm{wt} \%$ LiTFSI) leads to the title of 'polymer-in-salt' system. Angell et al. have reported that polymer-insalt electrolytes, such as superionic glasses that have a small amount of a low $\mathrm{M}_{\mathrm{w}}$ poly(propylene oxide) included, have greater conductivities than the salt-in-polymer electrolyte and that there is a decrease in $T_{\mathrm{g}} \cdot{ }^{16,17} \mathrm{~A}{ }^{7} \mathrm{Li}$ nuclear spin relaxation measurement was also performed on the polymer-in-salt electrolytes. The results of these studies found that there are serial decoupling structures with different relaxation modes in the liquids and that the conductivity of the polymer-in-salt electrolytes is dominated by the migration of free $\mathrm{Li}^{+} .17$ We attempted to measure the $\mathrm{Li}^{+}$ transference number, $t_{+}$, of the PEC-LiBF 4 $(44.4 \mathrm{wt} \%)$ electrolyte, and the value was estimated to be 0.49 at $100{ }^{\circ} \mathrm{C}$ (see Supplementary Figure S3 of Supplementary Information). This value is very high relative to the typical polyether-based electrolytes, for example, $t_{+} \sim 0.1$ for $\mathrm{PEO}_{2} \mathrm{LiBF}_{4}$ $(\sim 51.6 \mathrm{wt} \%)$ at $100{ }^{\circ} \mathrm{C} .{ }^{18}$ According to a previous report, the $t_{+}$drastically decreases with increasing salt concentration in PEO. ${ }^{18}$ Those authors suggested that the decreases in $t_{+}$are caused by the decrease in the number of free PEO segments and that the motion of $\mathrm{Li}^{+}$is hindered by the subsequent formation of ion-pairs. However, the PEC electrolyte has a very high $t_{+}$value, in spite of the high salt concentration. We believe that there may be many mobile $\mathrm{Li}^{+}$ions and free PEC segments that are not related to the tight coordination structure as observed in the PEO-based electrolytes.

\section{CONCLUSIONS}

The ion-conductive behavior of PEC-Li salt rubbery electrolytes was studied. The 
dependencies of ionic conductivity and $T_{\mathrm{g}}$ on the salt concentration revealed that the $\mathrm{LiCF}_{3} \mathrm{SO}_{3}$ and $\mathrm{LiClO}_{4}$ electrolytes exhibit typical polyether-like behavior. However, the LiBETI, $\mathrm{LiBF}_{4}$ and LiTFSI electrolytes were found to be much different such that the conductivity increases and $T_{\mathrm{g}}$ decreases with increasing salt concentration. The $\mathrm{Li}^{+}$transference number $\left(t_{+}\right)$of the PEC-LiBF $(44.4 \mathrm{wt} \%)$ electrolyte was very high, compared with the values of PEO-based electrolytes; it was estimated to be $\sim 0.5$ at $100^{\circ} \mathrm{C}$. PEC may have many mobile ions, which can migrate faster than coordinated cations, ionpairs and aggregated ions. Moreover, the existence of free PEC segments, which do not form strong coordinations with cations, most likely relates to the prevention of a large increase in $T_{\mathrm{g}}$, and consequently, the conductivity increases. We believe that the salt-rich PEC electrolytes incorporate decoupling structures, as observed in the salt-in-polymer system.

\section{ACKNOWLEDGEMENTS}

This work was supported in part by a Grant for Advanced Industrial Technology Development (Project ID: 11B01015c) in 2011 from the New Energy and Industrial Technology Development Organization (NEDO) of Japan. One of the authors (YT) also acknowledges financial support from the Inamori Foundation in 2011.

Yoichi Tominaga, Vannasa Nanthana and Daichi Tohyama

Department of Organic and Polymer Materials Chemistry, Tokyo University of Agriculture and Technology, Koganei, Tokyo, Japan E-mail: ytominag@cc.tuat.ac.jp

1 Tarascon, J. M. \& Armand, M. Issues and challenges facing rechargeable lithium batteries. Nature 414 359-367 (2001)

2 Scrosati, B. \& Garche, J. Lithium batteries: Status, prospects and future. J. Power Sources 195, 2419 2430 (2010).

3 Fenton, D. E., Parker, J. M. \& Wright, P. V. Complexes of alkali metal ions with poly(ethylene oxide). Polymer 14, 589 (1973).

4 Ratner, M. A. \& Shriver, D. F. Ion transport in solventfree polymers. Chem. Rev. 88, 109-124 (1988).

5 Bruce, P. G. Solid State Electrochemistry (Cambridge Univ. Press, Cambridge, 1995).

6 Takeoka, S., Ohno, H. \& Tsuchida, E. Recent advancement of ion-conductive polymers. Polym. Adv. Tech. 4, 53-73 (1993).

7 Nishimoto, A., Agehara, K., Furuya, N., Watanabe, T. \& Watanabe, M. High ionic conductivity of polyetherbased network polymer electrolytes with hyperbranched side chains. Macromolecules 32, 1541-1548 (1999).

8 Inoue, S., Koinuma, H. \& Tsuruta, T. Copolymerization of carbon dioxide and epoxide. J. Polym. Chem. Polym. Lett. 7, 287-292 (1969).
9 Inoue, S., Koinuma, H. \& Tsuruta, T. Copolymerization of carbon dioxide and epoxide with organometallic compounds. Makromol. Chem. 130, 210-220 (1969).

10 Sugimoto, Y. \& Inoue, S. Copolymerization of carbon dioxide and epoxide. J. Polym. Sci. Part A: Polym. Chem. 42, 5561-5573 (2004).

11 Wei, X. \& Shriver, D. F. Highly conductive polymer electrolytes containing rigid polymers. Chem. Mater. 10, 2307-2308 (1998)

12 Smith, M. J., Silva, M. M., Cerqueira, S. \& MacCallum, J. R. Preparation and characterization of a lithium ion conducting electrolyte based on poly(trimethylene carbonate). Solid State Ionics 140, 345-351 (2001).

13 Tominaga, Y., Shimomura, T. \& Nakamura, M. Alternating copolymers of carbon dioxide with glycidyl ethers for novel ion-conductive polymer electrolytes. Polymer 51, 4295-4298 (2010).

14 Nakamura, M. \& Tominaga, Y. Utilization of carbon dioxide for polymer electrolytes [II]: Synthesis of alternating copolymers with glycidyl ethers as nove ion-conductive polymers. Electrochim. Acta 57, 36-39 (2011).

15 Sylla, S., Sanchez, J. -Y. \& Armand, M. Electrochemical study of linear and crosslinked POE-based polymer electrolytes. Electrochim. Acta 37, 1699-1701 (1992)

16 Angell, C. A., Liu, C. \& Sanchez, E. Rubbery solid electrolytes with dominant cationic transport and high ambient conductivity. Nature 362, 137-139 (1993).

17 Fan, J., Marzke, R. F., Sanchez, E. \& Angell, C. A Conductivity and nuclear spin relaxation in superionic glasses, polymer electrolytes and the new polymer-insalt electrolyte. J. Non-Cryst. Solids 172-174, 1178 1189 (1994)

18 Munshi, M. Z. A., Owens, B. B. \& Nguyen, S. Measurement of $\mathrm{Li}^{+}$ion transport numbers in poly (ethylene oxide)-LiX complexes. Polym. J. 20, 597-602 (1988).

Supplementary Information accompanies the paper on Polymer Journal website (http://www.nature.com/pj) 